\title{
'Community of Learning' for African PhD students: Changing the scene of doctoral education?
}

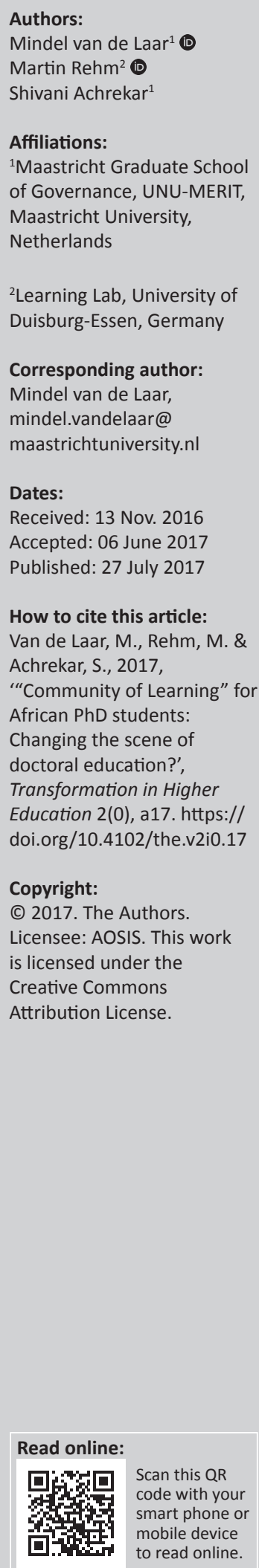

African $\mathrm{PhD}$ fellows who are interested in completing (part of) their research in Europe cannot always afford to leave their place of residency for prolonged periods of time. Yet, young researchers from African countries might be searching for particular guidance from experts in their field that might not be accessible in their home countries. Consequently, both PhD fellows and universities and postgraduate research institutes require more flexible educational formats that cater for these circumstances. With the growing availability and potential of online tools and methodologies, it is possible to choose from a range of options for $\mathrm{PhD}$ education. Communities of Learning $(\mathrm{CoL})$ have emerged as an approach to support the exchange of knowledge and experience among participants on the Internet. Participants can collaborate in developing research skills, while at the same time creating a feeling of belonging, which helps individuals to establish personal ties and relations. The paper introduces the research and educational project: Community for Learning for Africa (CoLA). It was designed to help participating actors from Africa and Europe to get and to stay connected online, to collaborate in joint training activities and projects, as well as to openly exchange ideas and thoughts, all in relation to underlying PhD research trajectories via the Internet. The paper offers results from a needs assessment undertaken in spring 2015, among $\mathrm{PhD}$ fellows and supervisors in Africa on what they would need CoLA to include, as well as template of what CoLA could include.

\section{Digital technology in PhD education}

Digital technology increasingly is infiltrating higher education. It is used to offer tools in research and teaching, as well as in administration and management. There is a large debate about the chances and risks of various degrees of digitisation of the academia. Some hope that digital technology will open new chances to access education and disseminate knowledge to a larger public whereas others fear that it will question national educational systems in a global commercial competition (Kim 2015).

In the discussion on digital technology in (higher) education, digital technology is often attributed a potential of transforming current educational systems and learning practices. The question is, to what extent digital technology has the potential to transform PhD education and to open up new horizons that otherwise could not have been addressed before. Or does digital technology 'only' improve PhD education to some extent, for example to improve opportunities to apply for education abroad or accelerate the access to international knowledge over the Internet (Wildy, Peden \& Chan 2015)? These 'improvements' should be seen as important and as prerequisites for scholars if they want to participate in the world-wide network of research and knowledge. Yet, they do not automatically constitute a transformation of education.

The following paper will address a new way of using digital technology in PhD education. With a Community of Learning (CoL) we explore how digital technology can help doctoral students in African universities to participate in global scholarly communication. In section two, we discuss ongoing global developments in PhD education, impacting doctoral programme access, discourse and outreach. With doctoral education in general becoming more global, reaching target groups beyond traditional full-time PhD students, developing new and different ways in which programmes are offered, and using digital technology to disseminate research results, the sector as a whole has been transformed in the last few decades. In section three, we cover the use of CoL in $\mathrm{PhD}$ education and debate how the use of CoL potentially improves and adds to the educational offerings. The case we discuss in section four and five, the Community of Learning for Africa (CoLA), combines both the changing doctoral education scene and use of $\mathrm{CoL}$, in order to support African PhDs in obtaining their degree. Section six includes a discussion around the improvements to be achieved with this type of approach. 


\section{The changing scene of doctoral education}

The increasing demand and supply of graduate education has led to a massification of graduate education (Clark 2007; Jablonski 2001; Pearson 1999:270; Pearson, Evans \& Macauley 2004:350; Wellington \& Sikes 2006; Wildy et al. 2015). Research is no longer solely conducted by a small, selected group within specialised institutions. Instead, there is a scale of options to follow a $\mathrm{PhD}$, including the traditional $\mathrm{PhD}$, professional doctorate, practice-based doctorate and parttime doctorate (Park 2007). With an extension of offerings from full-time traditional PhD programmes to part-time and professional $\mathrm{PhD}$ programmes, $\mathrm{PhD}$ research has become an activity that is increasingly incorporated in employees' regular job descriptions and everyday working environment (Lee \& Boud 2003; Wildy et al. 2015). Lifelong learning gains in importance, as employees need to continuously update their knowledge and skills to face the challenges and tasks of today's turbulent economic environment (Craswell 2007; Gherardi \& Nicolini 2000). Consequently, a growing number of employees has decided to become a doctoral student, return to university, acquire specialist knowledge and research skills (Pearson et al. 2004:348) and thereby enhance their chances to improve their career paths (Pearson 1999).

Since the early 2000s, we also see a gradual change within the programme offering of non-traditional doctoral programmes taking place. Initially differences between traditional doctoral education and professional or part-time doctoral education were mainly visible in a changed structure of the offered material. Over time the differences became more clear, with a move towards an adjustment of content to suit the knowledge acquisitions within the workplace better, towards shift in roles and responsibilities to be more demand-driven rather than supply-driven (Chapman 2008; Costley \& Lester 2014; Lester 2004; Park 2007; Scott et al. 2004; Wildy et al. 2015). Motivations to enrol in programmes include, among others, research skill development, professional development, intrinsic interest in the topic and interest in lifelong learning (Guerin, Jayatilaka \& Ranasinghe 2015). PhD trajectories with dyadic student or supervisor relationship (Malfroy 2005) are replaced with alternative communities to support the different learning process (Smith \& Bath 2006). Yet, while facing an increasingly diverse group of $\mathrm{PhD}$ fellows, the vast majority of providers still assume 'an on-campus, full-time student experience' (Pearson 1999:270).

The growing availability and potential of online learning tools offers universities and postgraduate research institutes considerable flexibility to cater to the diversity in doctoral learning and to foster their development (e.g. Allan \& Lewis 2006; Chalmers \& Keown 2006). In this context, CoL have been suggested to allow for an effective exchange of knowledge and experience between and among participants (Rehm 2013). Here, participants collaborate in developing research skills, while establishing and strengthening personal ties and relations, which in turn contribute to a feeling of belonging. As a result, learning processes and outcomes can be positively affected (Romsdahl \& Hill 2012).

\section{Communities of Learning for (doctoral) education}

More specifically, CoL have received a growing amount of attention among practitioners and researchers alike (e.g. Allan \& Lewis 2006; Rehm, Gijselaers \& Segers 2014, 2015; Rehm et al. 2016; Swan, Scarbrough \& Robertson 2002). CoL are defined as groups of people that 'engage in collaborative learning and reflective practice involved in transformative learning' (Paloff \& Pratt 2003:17). Furthermore, three distinctive aspects of $\mathrm{CoL}$ can be identified that differentiate the concept from alternative approaches, such as Communities of Practice (Lave \& Wenger 1991; Wenger, McDermott \& Snyder 2002; Wenger \& Snyder 2000). Firstly, CoL provide structure to the underlying learning processes. Secondly, CoL are monitored and facilitated by dedicated supporting staff. Finally, learning processes and outcomes are monitored, validated and assessed in order to safeguard the quality of the learning process and to legitimise all diplomas and degrees. A considerable amount of research has investigated the main characteristics of learning communities based on their growing importance and popularity (e.g. Alavi, Kayworth \& Leidner 2005; Roblyer \& Wiencke 2003; Stacey, Smith \& Barty 2004). However, considerable uncertainty remains about how to effectively construct a meaningful CoL for the new type of PhDs, namely working professionals who have started a (part-time) PhD trajectory. Previous research on the topic has already highlighted that research findings from similar groups of individuals (e.g. bachelor's and master's students) only have limited relevance for the context of working professionals (Rehm \& Van de Laar 2015). More specifically, research has revealed considerable differences in the activity patterns (Rehm, Giesbers \& Rienties 2009), as well as behaviour towards facilitators (Rehm et al. 2012) between regular students and working professionals. Additionally, working professionals have been shown to experience a certain level of apprehension when engaging in collaborative learning processes or providing feedback (Caffarella \& Barnett 2000). Malfroy (2005) has attributed this feeling to a perceived loss of authority and leadership. While they tend to certain responsibilities and tend to be accustomed to certain privileges in their daily (professional) work, the classroom setting can work against these circumstances, creating a level playing field, where they are expected to, among others things, to listen to and respond to feedback and possibly critique. Hence, an investigation of the social context of online learning in relation to behaviour and performance has been proposed (e.g. De Laat \& Lally 2003).

The main characteristics of $\mathrm{CoL}$ can be categorised into six aspects, namely open dialogue, flexibility, public and private spaces, informal discussions, interaction and rapid feedback (e.g. Amin \& Roberts 2006; Rienties et al. 2006). Taken together, these aspects make $\mathrm{CoL}$ an appealing option for providing teaching and learning opportunities for a diverse group of PhD fellows. 
Open dialogue: Everybody is stimulated and encouraged to contribute to each other's learning process.

Flexibility: Professional doctoral students are subject to considerable time constraints as they will remain a vibrant part of their working environments. A high level of flexibility allows individuals to remain active in the $\mathrm{CoL}$, continue their research irrespective of time and place, and show progress in their $\mathrm{PhD}$ trajectory.

Public and private community spaces: Public spaces stimulate the overall exchange of information and knowledge among all participating actors in a CoL. Private spaces foster discussions within a more confined space, allowing participants to more easily establish and strengthen personal ties with their fellow researchers (Gannon-Leary \& Fontainha 2007).

Informal discussions: Here, individuals can get to know each other better and stay connected. Scholars like Gannon-Leary and Fontainha (2007) have proposed that these types of discussions substantially contribute to the success of CoL by creating a sense of belonging and trust between the participating individuals.

Interaction: In order to bridge the often vast geographical distance between members of a CoL, participants should be stimulated to actively use various (a)synchronous communication tools, such as discussion forums or web conferencing portals (Hung \& DerThanq 2001). On the one hand, this allows for a more fluent and direct dialogue between peers. On the other hand, this also enhances the opportunities to communicate with (academic) supervisors.

Rapid feedback: Similarly to the previous aspect, in order to tackle the often vast geographical distance between members of a CoL, individuals should always receive (rapid) feedback when they pose questions or answers. This enhances the communication flow between all members of $\mathrm{CoL}$ and has advantageous effects on the overall performance of the individuals

\section{The need for capacity building of African PhD fellows}

Doing a $\mathrm{PhD}$ is a distinct career choice. When starting, it is often unclear to the fellow what kind of education he or she is actually starting and only once he or she is well under way does it becomes clear what challenges are taken up. Rough estimations indicate that about $20 \%$ of all starting full-time $\mathrm{PhD}$ students will not finish their $\mathrm{PhD}$ thesis, and thus will not obtain their degree (Jump 2013). This number is referring to $\mathrm{PhD}$ students, starting their $\mathrm{PhD}$ education in a university in a developed country, where facilities such as library access, journal subscriptions, Internet access and office space are available, and staff with capacity to supervise is present. It is thus likely that the failure rate of obtaining a PhD will be higher, when conditions to work on the PhD deteriorate.

In the case of the CoLA, we specifically focus on PhD students working in sub-Saharan Africa. More recently, research on higher education in Africa has become more prominent although research and literature is generally focused on the South African case and is mainly conducted by South African researchers. When research and literature does originate in other countries, authors tend to be affiliated to established universities, located in relatively well-off African countries (Van de Laar et al. 2016). Research shows that there is a clear need for capacity development in higher education in Africa. Enrolment in graduate programmes is low, dropout rates in undergraduate programmes are high and the higher education system in general remains inefficient (Cloete 2016b). Cloete, Mouton and Sheppard (2015) illustrate that enrolment in doctoral programmes, while high in South Africa, remains very low across the rest of Africa. With the majority of focus and funding aimed at primary and secondary education, the development of higher education is lagging behind and scientific output is limited. While the African quality and quantity of research output increased greatly over the past decade, the research output remains below $1 \%$ of total global research output (i.e. World Bank \& Elsevier 2014). There is a need to build capacity in universities; however, the supply of people qualified to increase skill levels is limited. Cloete et al. (2015) and Bunting et al. (2014) illustrate that enrolment in doctoral programmes has seen an overall increase. However, most of this increase is seen in South Africa and completion rates remain relatively low. Less than $20 \%$ of initially enrolled doctoral students graduate from South African programmes and this number is even lower in other countries (Bunting et al. 2014; Cloete et al. 2015). While $\mathrm{PhD}$ education is a good pathway to locally increase higher education capacity, there is a shortage of good applicants for doctoral programmes, a shortage of doctoral programmes, a shortage of in-house content capacity to supervise PhD students, a shortage of funding $\mathrm{PhD}$ research in Africa, a shortage of studies on how to build capacity in higher education and a shortage of studies on doctoral education in Africa (Cloete et al. 2015; Smit, Williamson \& Padayachee 2013; Van de Laar et al. 2016).

The relevance and need to boost higher education in Africa is clear. Yet, how to do so is less evident. The doctoral landscape is transforming, and the African continent feels the impact of this change beyond average. Enrolment in doctoral programmes remains low and graduation rates are even lower (Bunting et al. 2014; Cloete et al. 2015). The percentage of the population that graduated from doctoral programmes in developed countries ranges broadly between $1.5 \%$ and $2 \%$. In sub-Saharan African countries, recent numbers indicate that between $0 \%$ and $0.5 \%$ of the population has obtained their PhD degree (UNESCO UIS n.d.). ${ }^{1}$ With a globalising world and with transparent open application systems, we see an increase in mobility of the top students, creating brain drain in developing countries. However, institutions in developed countries will accept only a limited number of inhouse fellows. In addition, African individuals, specifically mid-career professionals, may not always be interested to move continents to be higher educated. With families to support and jobs to fulfil, they benefit more from better education at home. Educating people in developing countries

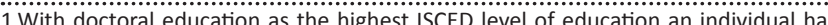
successully completed. This is usully measured with respect to the highest successfully completed. This is usually measured wich respect to the highest educational programme successfully completed which is typically certified by recognised qualification. Recognised intermediate qualifications are classified at a lower level than the programme itself. The most recent number between 2010 and 2015 was taken as reference. 
is costly and often only beneficial to the direct recipient if there is support from the community and family (Bharuthram \& Kies 2013; Cloete 2016a).

\section{Needs assessment among African PhD students}

In order to see if it is possible to support African $\mathrm{PhD}$ students by means of digital technology, specifically by offering a CoL, more knowledge was required on the specific needs of the potential users of the platform. In this context, we designed and implemented an electronic needs assessment among African PhD fellows and their supervisors. Direct information from local doctoral students on what content materials could be potentially useful for them to be offered, and what services would be interesting for local $\mathrm{PhD}$ fellows and their supervisors to use or benefit from sharing. The needs assessment supported the creation of a network of universities, faculties, departments and institutions engaged in $\mathrm{PhD}$ education that shares content interest, and an inventory of full professors in the field willing to participate in CoLA. The needs assessment adds to better understanding of the potential scale of users of the platform and ensures future willingness to cooperate with us jointly on the initiative ${ }^{2}$ (Van de Laar et al. 2016)

The needs assessment survey was developed based on examples of similar surveys, as well as literature guidance on what is essentially needed in higher educational institutes in Africa (Van de Laar et al. 2016). ${ }^{3}$ There was a clear target population for our needs assessment, being $\mathrm{PhD}$ fellows and their supervisors based in a sub-Saharan African institute. Based on publications within the Web of Science, we created a list of approximately 16000 researchers, working in the target research area of our study. ${ }^{4}$ Between 26 March 2015 and 20 April 2015, data were collected using an electronic survey tool. A total of 269 respondents completed the survey. These responses are not representative for the target population in Africa, but the data collected are sufficiently rich to serve the purpose of verifying if our intended CoLA offerings are in line with the actual needs of $\mathrm{PhD}$ fellows in Africa. Respondents to our survey are more likely to come from South Africa, Zimbabwe and Nigeria than other countries, and are more likely to be employed by better established universities within their countries, and from cities with better infrastructure such as Internet access. The sample is further biased towards individuals that have

2.CoLA is an initiative of UNU-MERIT and Maastricht University. We obtained University Funds Limburg/SWOL subsidy to do a needs assessment, map the actors University Funds Limburg/SWOL subsidy to do a needs assessment, map the actors in Africa interested in PhD capacity building, define activities and courses needed to
support the PhD fellows in Africa, as well as support their supervisors to execute support the PhD fellows in Africa, as well as support their supervisors to execute
their supervision job. We obtained a WUN subsidy to pilot the first platform among PhD fellows of selected African universities.

3.The first preliminary instrument was elaborately discussed with African PhD students and African professors in the Netherlands, who from personal experience know the situation in one or more institutions (four interviews). The adjusted instrument was tested using an online survey link. During this test phase, African in-house PhD students filled out the instrument, while research assistants monitored their answering behavior in person. Feedback was discussed and small monitored their answering behavior in person. Feedback was discussed and small changes were made to the instrument. Lastly, we piloted among purposefully selected African master's and PhD students located in sub-Saharan Africa and asked
them to test the instrument, before sending it out in the mass mailing.

4.Individuals working in the research area poverty $O R$ migration $O R$ conflict $O R$ crisis OR institutions OR economic development OR capacity building OR policy OR governance OR technology OR innovation OR entrepreneurship. already published a paper because of the nature of our sampling with $57 \%$ of respondents being supervisors and the remaining $43 \%$ PhD fellows. Despite this, a snowball feature (asking respondents to forward the survey to their peers) allowed broadening to include fellows that had not published yet (Van de Laar et al. 2016).

Of the 269 respondents in the survey, 36\% were female and $64 \%$ were male. More than half hold a $\mathrm{PhD}(58 \%), 35 \%$ hold a master's degree and are currently working on their $\mathrm{PhD}$ and $7 \%$ indicate to have a bachelor's or other degrees, obtained from institutions both in African countries as well as in western Europe, North or South America, or Asia. Respondents currently work most often in African institutions, mainly from South Africa, followed by Nigeria, Zimbabwe and fewer responses came from the other countries as illustrated in Figure 1. Several respondents currently work in developed countries, but filled out the survey based on past experiences.

In line with global transforming the doctoral education landscape literature, we notice that $50 \%$ of the $\mathrm{PhD}$ fellows cannot be considered traditional $\mathrm{PhD}$ fellows. They are not paid to do their $\mathrm{PhD}$ (see Figures 2 and 3). Of the $\mathrm{PhD}$ fellows, $15 \%$ are teaching staff, $10 \%$ are research staff and $24 \%$ are not funded or self-funded for the PhD. Half of the people indicate that the $\mathrm{PhD}$ research is not financially their main source of living.

About $95 \%$ of the responding PhD fellows indicate that they have one or more assigned supervisors. Supervisors are consulted on a regular basis, mainly in person or via email. Fellows feel supported by their supervisors, but also indicate that in almost all elements of the research cycle they appreciate more support. Figure 4 shows that both students and supervisors indicate a need for support in defining research questions, doing literature reviews, data collection and analysis and skills development. The responses of supervisors and fellows almost perfectly aligned, which indicates the request for support comes from staff and students.

In the case of education in Africa, public institutions, particularly those in rural areas, do not have the capacity or funding to give their students access to technology or ICT education in general. Most students get their first computer lessons during their first year of university. Consequently, African PhDs are already disadvantaged, having just learned a skill that students in more developed countries pick up at the primary school level. Moreover, they continue to have poor access to Internet and ICTs in general outside of major cities (Bharuthram \& Keis 2013; Evans \& Le Roux 2016; Marais \& Blignaut 2016). It therefore comes as no surprise that respondents to our survey asked for more interaction and feedback from supervisors, better access to literature and training, user-friendly platforms and easy access to learning materials and softwares, both online and offline. 


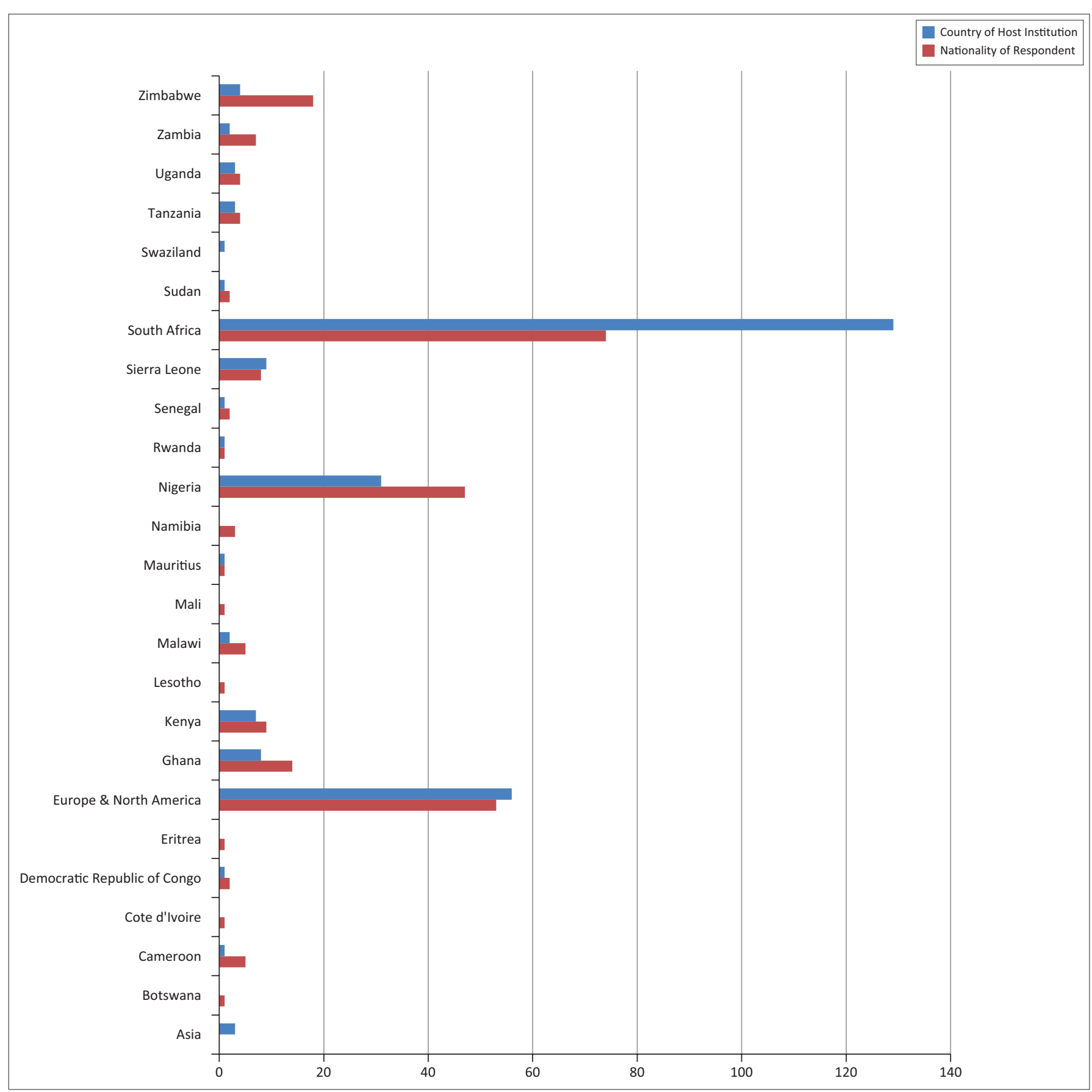

Source: CoLA Needs Assessment 2015, MGSoG/UNU-MERIT, Maastricht University

FIGURE 1: Number of respondents per country, by country of host institution and nationality of respondents, including non-Africans.

\section{A community of learning for African PhD students}

The overall aim of the UNU-MERIT \& MGSoG is to set up a Community for Learning for Africa (CoLA) on the general topic of 'Innovation' and 'Governance', where participants from a wide variety of target groups are enabled to get connected and stay in touch, collaborate in learning activities and projects, as well as to openly exchange ideas and thoughts. More specifically, the envisioned target groups of the CoLA include PhD fellows as main receivers of support and researchers, working professionals and alumni as providers of knowledge. PhD students will remain affiliated with their home university, their supervisory teams stay in place and all services offered by CoLA are complementary to the already offered $\mathrm{PhD}$ education and support by the home university.

The basis for this community will be a range of different activities that will build on three main pillars, namely courses, repository and community. Each of these aspects will contribute to an active exchange of information, experiences, knowledge and expertise, as well as the further (academic) development of participating actors. In order to be functional, CoLA will need to take into account the limited infrastructural support locally (e.g. lack of electricity, lack of Internet and 


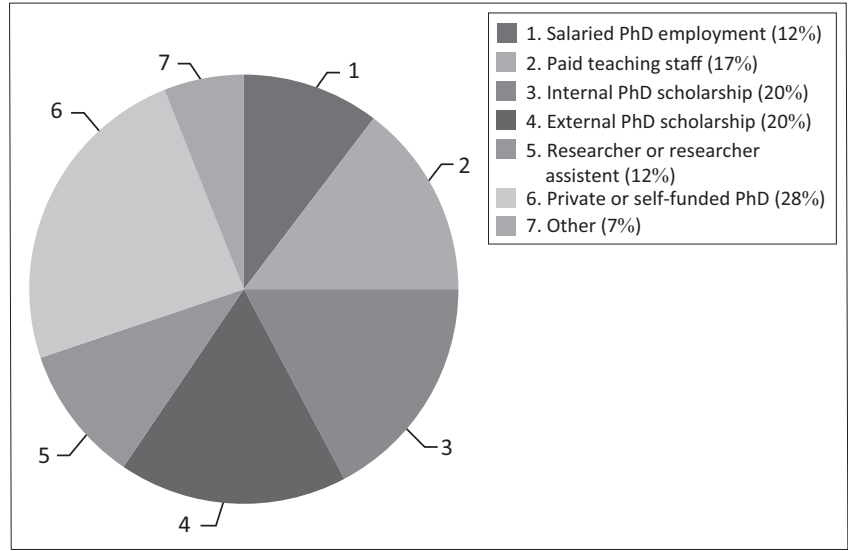

Source: Community for Learning for Africa Needs Assessment 2015, MGSoG/UNU-MERIT, Maastricht University

FIGURE 2: Position of the PhD fellow (number of respondents by job title or position name in which participants work on their dissertation).

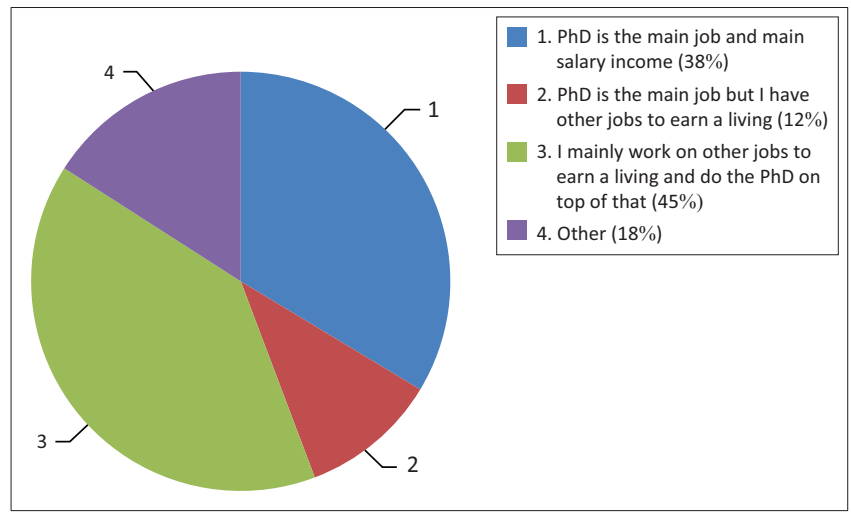

Source: Community for Learning for Africa Needs Assessment 2015, MGSoG/UNU-MERIT Maastricht University

FIGURE 3: Main income for African PhD fellows (number of respondents by main source of income).

requirement to use telephone), the $24 / 7$ availability (to service people with other commitments to use CoLA at a moment they have time to work on their $\mathrm{PhD}$ - based on the new type of $\mathrm{PhD}$ engagement), the complementarity of services (as CoLA does not compete with supervisors, but functions as add-on) and the sustainability criteria (with limited input from all partners, and increased knowledge sharing by participants - the community aspect).

The CoL will introduce the main concepts and methodologies related to the two overarching topic domains (e.g. Innovation and Governance), which will include a wide range of educational activities. The underlying goal is to create an environment in which theory and practice are effectively interlinked and an open exchange between the two is stimulated. More specifically, CoLA will provide access to three types of CoL:

1. Online training modules: The modules provide the means for members of all identified target groups to engage in (collaborative) learning activities, thereby expanding the knowledge and skills of all participants.

2. Online research support: While young researchers (e.g. PhD fellows) have access to valuable expertise in their home institutes, they might sometimes be looking for additional guidance from (international) experts. This can range from occasional questions to structural $\mathrm{PhD}$ supervision projects. CoLA will cater for these types of support by providing a portal where young researchers can communicate with international experts on an ongoing basis (via various communication channels).

3. Repository of services: With an increased availability of free of charge open access research support services, the need to develop new material becomes small. An inventory of links to those services, with the option to add new items and contribute to the repository by all participants

As the needs assessment shows, there is a clear need for support in the area of research skills and topic specific knowledge. Institutions of higher education are continuously looking for new ways and methods to teach and train their target groups. In this context, the use of ICT-tools and the development of online learning methodologies constitute a vital development that has received ever-increasing attention. This demand is mainly driven by the increasing diversity of learners from various educational backgrounds, and although international participants might fulfil all necessary application requirements, their educational backgrounds are often so diverse that they are effectively hindered from starting their studies. Additionally, new target groups, such as PhDs from African countries, cannot afford to leave their place of residency for prolonged periods of time, therefore requiring flexible educational formats that cater for these types of circumstances. Furthermore, in the context of $\mathrm{PhD}$ supervision, past experience has shown that young researchers from African countries might sometimes be searching for particular guidance and support that might not be easily accessible at their home institutes. As a consequence, numerous types and formats for online modules and support mechanisms have been developed. In this context, CoL have been suggested as a useful tool to meet these new requirements, by stimulating collaborative knowledge sharing among diverse individuals within social networks and irrespective of time and place.

In order to overcome these challenges, CoLA will begin with the development and implementation of online modules that have been identified as important building blocks in the educational process of the target groups in question. An initial set of courses that will be developed contains basic methodology courses, but also topic-specific introduction courses as well as topic-deepening courses.

The sustainability of the community is based on two main activities. Firstly, CoLA will provide a means to construct a growing repository of information and resources, as well as research activities. The repository will include access to external websites and support services that are offered open access and are related to the support we offer to our participants but also to live video conferences, lectures, podcasts and other multimedia resources. With participants able to comment on the items posted or items that are lacking, the project team will be supported with valuable feedback and suggestions, which can then proactively be incorporated in the further development of the CoLA repository. Secondly, 


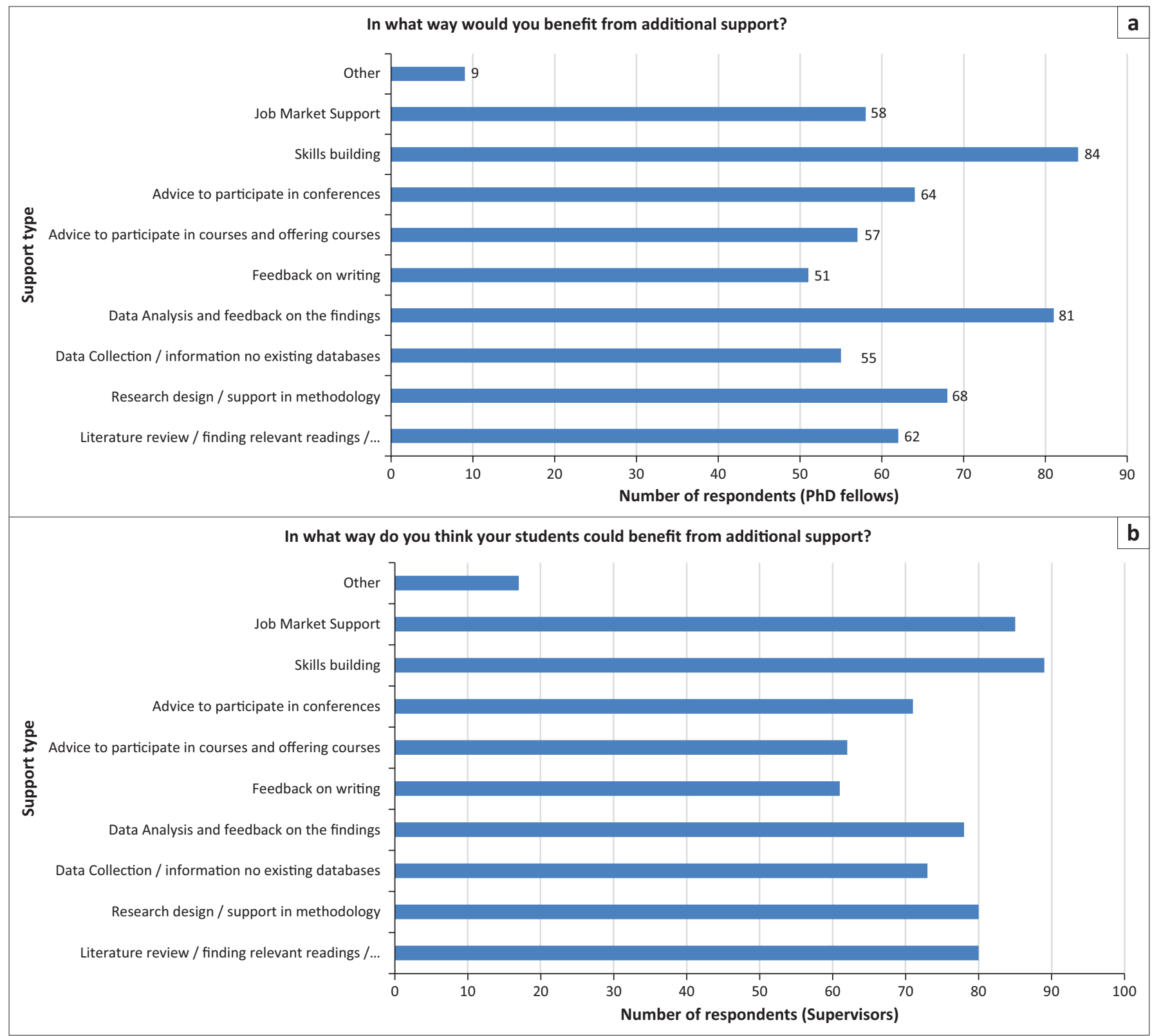

Source: Community for Learning for Africa Needs Assessment 2015, MGSoG/UNU-MERIT, Maastricht University

FIGURE 4: Additional support required from Community for Learning for Africa (CoLA) platform.

building on the interest of CoLA PhD beneficiaries today, the CoLA participants will foster the creation of an alumni network, which can serve multiple purposes. The purpose of the alumni network is not only to create a network of African graduates working in related topics, but also to create an environment for lifelong learning. The network can also assist matching the demand for advice and support from more junior participants (e.g. PhD fellows) with the academic knowledge and expertise of more senior participants (e.g. working professionals and researchers). The main benefit of keeping CoLA alumni involved will be a growing support network of researchers based in Africa, which will hopefully foster research output on the African continent through cooperation and support of each other's activities. CoLA will provide the possibility for $\mathrm{PhD}$ fellows from different participating institutes and organisations to connect with and identify 'like-minded' colleagues, who work in similar research fields and who can potentially become partners in future research or project activities.

It is generally acknowledged that alumni, as well as (inter) national partners, can play a crucial role in contributing to the career opportunities of current PhD fellows. Similarly, if these groups are more actively incorporated in activities such as career services, it would also be possible to create a stronger link between the university and the alumni, which in turn would facilitate the process of 'staying connected'. While there are already databases containing vacant jobs and internships, faculties and institutes could better capitalise on their personal contacts with alumni and other external partners. This in turn could create favourable conditions contributing to more tailor-made solutions for $\mathrm{PhD}$ fellows. As a result, this also provides additional benefits for the applicable alumni and external partners providing a job 
opportunity, as the matching process between 'demand' and 'supply' would be enhanced.

In order to contribute to the development of such a matching process, CoLA will be based on the virtual learning environment Moodle, which will be hosted by UNU-MERIT \& MGSoG. This environment is passwordprotected, only available to identified community members (African PhD fellows, their supervisors and other contributing actors). Here, interactivity will really be a collaborative process, allowing all participating actors to play an active role in this process.

\section{Conclusions}

With the changing PhD landscape, including more diverse ways to obtain a $\mathrm{PhD}$, a global playground and opportunity to use technology to enhance lifelong learning, this paper discusses the opportunities to use a CoL to specifically service sub-Saharan African PhD students. As literature suggests and research output shows, academic productivity in sub-Saharan Africa is lagging behind the rest of the world, and targeting $\mathrm{PhD}$ students to build academic capacity locally might be a valuable way to support scientific development. Theoretically, an additional support service for $\mathrm{PhD}$ education, based on a $\mathrm{CoL}$, can benefit the scholarly development of PhD students. It can address new and traditional groups of $\mathrm{PhD}$ students and offer new ways to develop research skills to become part of a global community of scholars. Our needs assessment, held among African PhD students and their supervisors, indicated the necessity to systematically support the development of research skills and topic knowledge in such a community. It can be supported with a virtual environment that provides access to scholarly materials as well as a communicative tool for social exchange and supervision.

What is specifically innovative about the current proposal is the extra layer of support that is developed in the virtual environment, offered by external parties combined in an online community. Actors, not institutionally connected to the $\mathrm{PhD}$ fellow, cooperate in the CoL with the aim of increased knowledge building and improved dissemination.

Yet, while innovative in approach, and potentially transformative for the $\mathrm{PhD}$ sector, the success depends on various factors, and successful implementation remains to be seen. With CoLA offered on an open platform, and in principle being open for all African doctoral students and their supervisors, access to the material is secured. Yet, the actual use of the platform by the fellows, enrolling in classes, engaging in debate and feedback loops and benefitting from and contributing to a repository of information that is up to date and valuable, is not yet fully tested. Even though $\mathrm{PhD}$ fellows indicate in the needs assessment that they would value these services if offered, we have not been able to evaluate the actual use of the platform by PhD fellows yet. With time being scarce, even more so when the $\mathrm{PhD}$ is done part-time, in addition to being employed, it remains to be seen that PhD fellows choose to use the services offered consistently. Until the platform has been more thoroughly piloted and tested for a prolonged period of time, we cannot fully assess if there are positive results coming from using the CoL. Learning analytics about the actual use of the services, course completion rates, and paper publication data must be collected in order to assess true impact. Before we can begin to speak about transformation, we would need to see voluntary consistent use of the add-on service, positive outcomes in terms of publications and course completion and longer term capacity development and even contributions to the CoL. In future research we want to further analyse what measures in CoL help to improve the scholarly development of $\mathrm{PhD}$ students and what measures could contribute to a further transformation of doctoral education.

\section{Acknowledgements}

The authors thank Limburg University Fund SWOL for funding the needs assessment of CoLA and the Worldwide Universities Network for the RDF funding to pilot the platform. The authors thank Prof. Michael Kerres (Learning Lab, University of Duisburg-Essen), the participants of the AACE conference 2016 in Vancouver, the participants of the e-Learning Africa 2015 conference in Addis Ababa and the participants of the APPAM spring conference 2015 in Washington DC for their feedback. The authors thank Lucy Larbi and Friederike Rühmann for their research assistance in the needs assessment.

\section{Competing interests}

The authors declare that they have no financial or personal relationships which may have inappropriately influenced them in writing this article.

\section{Authors contributions}

M.v.d.L. is project leader of the CoLA project, and responsible for the needs assessment design and analysis, and pilot project implementation. S.A. was research assistant implementing the needs assessment and project coordinator of the CoLA pilot project. M.R. made conceptual contributions on CoL and was advisor on the CoLA project.

\section{References}

Alavi, M., Kayworth, T.R. \& Leidner, D.E., 2005, 'An empirical examination of the influence of organizational culture on knowledge management practices', Journal of Management Information Systems 22(3), 191-224. https://doi.org/10.2753/ MIS0742-1222220307

Allan, B. \& Lewis, D., 2006, 'The impact of membership of a virtual learning community on individual learning careers and professional identity', British Journal of Educational Technology 37(6), 841-852. https://doi.org/10.1111/j.1467-8535.2006.00661.x

Amin, A. \& Roberts, J., 2006, Communities of practice: Varieties of situated learning, draft paper prepared for EU Network of Excellence Dynamics of Institutions and Markets in Europe (DIME), viewed 21 August 2007, from http://cops.dime-eu. org/files/active/O/Amin_Roberts.pdf.

Bharuthram, S. \& Kies, C., 2013, 'Introducing e-learning in a South African higher education institution: Challenges arising from an intervention and possible responses', British Journal of Educational Technology 44(3), 410-420. https://doi. org/10.1111/j.1467-8535.2012.01307.x

Bunting, I., Cloete, N. \& Van Schalkwyk, F., 2014, An empirical overview of eight flagship universities in Africa: 2001-2011, Center for Higher Education
Transformation, viewed 16 June 2017, from https://www.chet.org.za/books/ empirical-overview-eight-flagship-universities-africa-2001-2011 
Caffarella, R.S. \& Barnett, B.G., 2000, 'Teaching doctoral students to become scholarly writers: The importance of giving and receiving critiques', Studies in Higher writers: The importance of giving and receiving critiques', Studies
Education 25(1), 39-52. https://doi.org/10.1080/030750700116000

Chalmers, L. \& Keown, P., 2006, 'Communities of practice and professional development', International Journal of Lifelong Education 25(2), 139-156. https:// doi.org/10.1080/02601370500510793

Chapman, A.P., 2008, 'The professional doctorate in transnational education: A narrative inquiry into student experience', in L. Dunn and M. Wallace (eds.), Teaching in transnational higher education: Enhancing learning for offshore international students, pp. 171-179, Routledge Falmer, London.

Clark, L., 2007, 'Motivating factors for the professional development of a cohort of professional doctorate students in education', unpublished thesis, Victoria University, Melbourne, viewed 16 June 2017, from https://core.ac.uk/ display/10827071

Cloete, N., 2014, 'The South African higher education system: Performance and policy', Studies in Higher Education 39(8), 1355-1368. https://doi.org/10.1080/03 075079.2014.949533

Cloete, N., 2016a, Free higher education: Another self-destructive South African policy Center for Higher Education, Cape Town, South Africa, viewed May 2017 from https://www.chet.org.za/papers/third-force-south-african-higher-educationactivism

Cloete, N., 2016b, The third force in South African Higher Education Activism, Center for Higher Education, Cape Town, South Africa. viewed May 2017 from http:// www.chet.org.za/papers/third-force-south-african-higher-education-activism

Cloete, N., Mouton, J. \& Sheppard, C., 2015, Doctoral education in South Africa, African Minds. Center for Higher Education, Cape Town, South Africa. viewed May 2017 from https://www.chet.org.za/books/doctoral-education-south-africa

Craswell, G., 2007, 'Deconstructing the skills training debate in doctoral education', Higher Education Research and Development 26(4), 377-391.

De Laat, M. \& Lally, V., 2003, 'Complexity, theory and praxis: Researching collaborative learning and tutoring processes in a networked learning community', Instructional Science 31(1-2), 7-39. https://doi.org/10.1023/A:1022596100142

Evans, N.D. \& Le Roux, J., 2016, 'Modelling the acceptance and use of electronic learning at the University of Zululand' South African Journal of Libraries and Information Science 81(2), 26-38. https://doi.org/10.7553/81-2-1562

Fowler, C.J.H. \& Mayes, J.T., 1999, 'Learning relationships from theory to design', ALT-J 7(3), 6-16. https://doi.org/10.1080/0968776990070302

Gannon-Leary, P. \& Fontainha, E., 2007, Communities of practice and virtual learning communities: Benefits, barriers and success factors, Elearning Papers 5, 20-29. ISSN 1887-1542

Gherardi, S. \& Nicolini, D., 2000, 'The organizational learning of safety in communities of practice', Journal of Management Inquiry 9(1), 7-18. https://doi. org/10.1177/105649260091002

Guerin, C., Jayatilaka, A. \& Ranasinghe, D., 2015, 'Why start a higher degree by research? An exploratory factor analysis of motivations to undertake doctoral studies', Higher Education Research and Development 34(1), 89-104. https://doi. org/10.1080/07294360.2014.934663

Hung, D.W.L. \& Der-Thanq, C., 2001, 'Situated cognition, Vygotskian thought and learning from the communities of practice perspective: Implications for the design of web-based learning', Educational Media International 38(1), 3-12. https://doi. of web-based learning', Educationd
org/10.1080/09523980121818

Jablonski, A., 2001, 'Doctoral studies as professional development of educators in the United States, European', Journal of Teacher Education 24(2), 215-221. https:// doi.org/10.1080/02619760120095606

Jump, P., 2013, 'PhD completion rates, 2013', Times Higher Education, viewed 16 June 2017, from https://www.timeshighereducation.com/news/phd-completionrates-2013/2006040.article

Kim, J.H., 2015, 'Pedagogical approaches to media literacy education in the United States', in M.N. Yildiz \& J. Keengwe (eds.), Handbook of research in media literacy in the digital age, pp. 52-74, Hershey PA, IGI Global. Hershey, PA. https://doi. org/10.4018/978-1-4666-9667-9

Lave, J. \& Wenger, E., 1991, Situated learning: Legitimate peripheral participation, Cambridge University Press, Cambridge, UK.

Lee, A. \& Boud, D., 2003, 'Writing groups, change and academic identity: Research development as local practice', Studies in Higher Education 28(2), 187-200. https://doi.org/10.1080/0307507032000058109

Lester, S., 2004, 'Conceptualising the practitioner doctorate', Studies in Higher Education 29(6), 757-770. https://doi.org/10.1080/0307507042000287249

Malfroy, J., 2005, 'Doctoral supervision, workplace research and changing pedagogic practices', Higher Education Research and Development 24(2), 165-178. https:// doi.org/10.1080/07294360500062961

Marais, D.V.V. \& Blignaut, S., 2016, 'e-Literacy skills mismatches at a South African university: A case study', pp. 242-252, presented at the EdMedia: World Conference on Educational Media and Technology, Association for the Advancement of Computing in Education (AACE), viewed 16 June 2017, from Advancement of Computing in Education
https://www.learntechlib.org/p/172958

Park, S., 2007, Redefining the doctorate, discussion paper, The Higher Education Academy, York.
Paloff, R. \& Pratt, K., 2003, The virtual student: A profile and guide to working with online learners, Jossey-Bass, San Francisco, CA.

Pearson, M., 1999, 'The changing environment for doctoral education in Australia: Implications for quality management, improvement and innovation', Higher Education Research and Development 18(3), 269-287. https://doi. org/10.1080/0729436990180301

Pearson, M., Evans, T. \& Macauley, P., 2004, 'The working life of doctoral students: Challenges for research education and training', Studies in Continuing Education 26(3), 347-353. https://doi.org/10.1080/0158037042000265917

Rehm, M., 2013, Unified yet separated - Empirical study on the impact of hierarchica positions within communities of learning, Uitgeverij Boekenplan, Maastricht.

Rehm, M., Galazka, A., Gijselaers, W. \& Segers, M., 2012, 'Managing communities of learning for working professionals: The impact and role of facilitators', paper presented at the EDiNEB 2-4 May, Haarlem, the Netherlands.

Rehm, M., Giesbers, B. \& Rienties, B., 2009, 'Comparing communities of learning for incoming bachelor students \& working professionals', in N. Brouwer, B. Giesbers, B. Rienties \& L. van Gastel (eds.), Student mobility and ICT: Dimensions of transition, pp. 143-150, FEBA ERD Press, Amsterdam.

Rehm, M., Gijselaers, W. \& Segers, M., 2014, 'Effects of hierarchical levels on social network structures within communities of learning', Frontline Learning Research 2(2), 38-55. https://doi.org/10.14786/flr.v2i2.85

Rehm, M., Gijselaers, W. \& Segers, M., 2015, 'The impact of hierarchical positions on learning', International Journal of Computer-Supported Collaborative Learning 10(2), 117-138.

Rehm, M., Mulder, R.H., Gijselaers, W. \& Segers, M., 2016, 'The impact of hierarchical positions on the type of communication within online communities of learning', Computers in Human Behavior 58, 158-170. https://doi.org/10.1016/j. chb.2015.12.065

Rehm, M. \& van de Laar, M., 2015, 'The potential of communities of learning for dual career PhD programs - A case study', in A. Dailey-Hebert \& K.S. Dennis (eds.), Transformative perspectives and processes in higher education, vol. 6, pp. 155-177, Springer International Publishing, Cham, Switzerland. https://doi. org/10.1007/978-3-319-09247-8 9

Rienties, B., Tempelaar, D., Waterval, D., Rehm, M. \& Gijselaers, W., 2006, 'Remedial online teaching on a summer course', Industry and Higher Education 20(5), 327-336. https://doi.org/10.5367/000000006778702300

Roblyer, M.D. \& Wiencke, W.R., 2003, 'Design and use of a rubric to assess and encourage interactive qualities in distance courses', American Journal of Distance Education 17(2), 77-98. https://doi.org/10.1207/S15389286AJDE1702_2

Romsdahl, R.J. \& Hill, M.J., 2012, 'Applying the learning community model to graduate education: Linking research and teaching between core courses', Teaching in Higher Education 17(6), 722-734. https://doi.org/10.1080/13562517.2012.678325

Scott, D., Brown, A., Lunt, I. \& Thorne, L., 2004, Professional doctorates: Integrating professional and academic knowledge, Society for Research into Higher Education \& Open University Press, Maidenhead.

Smit, B., Williamson, C. \& Padayachee, A., 2013, 'PhD capacity-building, from aid to innovation: The SANPAD-SANTRUST experience', Studies in Higher Education 38(3), 441-455. https://doi.org/10.1080/03075079.2013.773218

Smith, C. \& Bath, D., 2006, 'The role of the learning community in the development of discipline knowledge and generic graduate outcomes', Higher Education 51(2), 259-286. https://doi.org/10.2307/29734977

Stacey, E., Smith, P.J. \& Barty, K., 2004, 'Adult learners in the workplace: Online learning and communities of practice', Distance Education 25(1), 107-123. https://doi.org/10.1080/0158791042000212486

Swan, J.A., Scarbrough, H. \& Robertson, M., 2002, 'The construction of "communities of practice" in the management of innovation', Management Learning 33(4), 477-496. https://doi.org/10.1177/1350507602334005

UNESCO UIS, n.d., UIS, viewed 17 March 2017, from http://data.uis.unesco.org/

Van de Laar, M., Achrekar, S., Larbi, L. \& Rühmann, F., 2016, Proceedings of EdMedia World Conference on Educational Media and Technology, Association for the Advancement of Computing in Education (AACE), pp. 506-522, viewed 1 September 2016, from https://www.learntechlib.org/p/172996

Wellington, J. \& Sikes, P., 2006, “'A doctorate in a tight compartment": Why do students choose a professional doctorate and what impact does it have on their personal and professional lives?', Studies in Higher Education 31(6), 723-734. https://doi.org/10.1080/03075070601004358

Wenger, E., McDermott, R. \& Snyder, W.M., 2002, Cultivating communities of practice, Harvard University Press, Boston, MA.

Wenger, E. \& Snyder, W., 2000, 'Communities of practice: The organizational frontier' Harvard Business Review 78(6), 139-146, viewed on 15 May 2016 from https:// hbr.org/2000/01/communities-of-practice-the-organizational-frontier

Wildy, H., Peden, S. \& Chan, K., 2015, 'The rise of professional doctorates: Case studies of the doctorate in education in China, Iceland and Australia', Studies in Higher Education 40(5), 761-744. https://doi.org/10.1080/03075079.2013.842968

World Bank \& Elsevier, 2014, A decade of development in sub-Saharan African Science, Technology, Engineering \& Mathematics Research, viewed 15 May 2016, from http://documents.worldbank.org/curated/en/237371468204551128/pdf/91016 OWPOP126900disclose09026020140.pdf 